\title{
Safety and efficacy of the subdermal etonogestrel contraceptive implant Implanon ${ }^{\circledR}$
}

\section{Rob Beerthuizen}

Gynaecologist, Director of the Dutch Foundation for Contraception, Winterswijk, The Netherlands

\section{Correspondence to} Dr Rob Beerthuizen, Dutch Foundation for Contraception, B. Stegemanstraat 28, Winterswijk 7101AS, The Netherlands; beerthuizen@ anticonceptie-online.nl

Received 28 September 2016 Revised 7 November 2016 Accepted 9 November 2016 Published Online First 13 December 2016

\section{SLinked}

http://dx.doi.org/10.1136/ jpprhc-2015-101375

\section{CrossMark}

To cite: Beerthuizen R. J Fam Plann Reprod Health Care 2017:43:118.
A prospective study in this journal issue compares the effects on maternal bone turnover during lactation of subdermal implant compared with copper intrauterine device (IUD) use. ${ }^{1}$ It is interesting because publications about the influence of hormonal contraceptives on the health of the lactating woman herself are rare. This study's advantage is that bone mineral density mostly is measured using dual-energy X-ray absorptiometry or a similar modality, rather than relying on biochemical analyses of serum and urine samples. ${ }^{1}$ Its weak points are the relatively small numbers of participating women and the fact that this is a singlecentre study. However, it does offer some reassurance regarding the safety for the mother of this highly effective type of long-acting reversible contraceptive (LARC) even during lactation.

Most studies of hormonal contraceptives in lactating women have focused on the effect of the contraceptive on lactation itself, and on infant growth and well-being. A systematic review of progestogen-only contraception found no adverse effects on breastfeeding outcomes, or outcomes related to infant growth, health or development. This lack of negative outcomes was maintained when progestogen-only implants were started within the first 6 weeks postpartum. In addition, breastfeeding duration did not differ between users of an etonogestrel implant compared with $\mathrm{Cu}$-IUD users over 3 years. ${ }^{2}$

LARCs, including the etonogestrel subdermal implant and the levonorgestrelreleasing intrauterine system, are the most effective methods of contraception, even more effective than female sterilisation. In a 3-year prospective study comparing LARC methods with non-LARC methods, LARC methods were 20 times more effective than the non-LARC methods over all time periods. ${ }^{3}$ In keeping with this, the American College of Obstetricians and Gynecologists (ACOG) recently published a report encouraging the application of LARCs immediately postpartum. It recommends among other things that women should be counselled prenatally about the option of immediate postpartum application of a LARC method. ${ }^{4}$

However, as well as clinicians, health authorities need to be more aware of the power of LARC methods to provide safe and effective contraception, reduce teenage pregnancies, unintended pregnancy, unsafe abortion and maternal deaths. In addition to their harm to women's health, they also impact detrimentally on social well-being. Providing contraception including LARCs at no cost to the user should be standard for all women after they have received adequate counselling to ensure that the chosen contraceptive method meets their needs. $^{3}$

Competing interests None declared.

Provenance and peer review Commissioned; internally peer reviewed.

\section{REFERENCES}

1 Duvan CI, Onaran Y, Keskin EA, et al. The effect of etonogestrel contraceptive implant $\left(\right.$ Implanon ${ }^{\circledR}$ ) on bone metabolism during lactation. J Fam Plann Reprod Health Care 2017;43:113-17.

2 Phillips SJ, Tepper NK, Kapp N, et al. Progestogen-only contraceptive use among breastfeeding women: a systematic review. Contraception 2016;94:226-252.

3 Birgisson NE, Zhao Q, Secura GM, et al. Preventing unintended pregnancy: the contraceptive CHOICE project in review. $J$ Womens Health 2015;24:349-353.

4 American College of Obstetricians and Gynecologists. Committee Opinion No. 670: Immediate postpartum long-acting reversible contraception. Obstet Gynecol 2016;128: e32-e37. 